\title{
Factores de Virulencia asociados a especies zoonóticas de Campylobacter spp.
}

\author{
Lisette Lapierre A. ${ }^{1}$ \\ ${ }^{1}$ Departamento de Medicina Preventiva, Facultad de Ciencias Veterinarias y Pecuarias, Universidad de Chile. \\ Santa Rosa 11735, La Pintana, Santiago. \\ Email: 1lapierre@uchile.cl
}

\begin{abstract}
Resumen
Campylobacter spp., es una bacteria Gram negativa causante de una de las enfermedades transmitida por los alimentos más prevalente en el mundo, la campilobacteriosis. Esta bacteria puede encontrarse en una gran cantidad de animales silvestres y domésticos, así como también en agua, tierra, productos alimenticios pero el más importante reservorio lo constituyen las aves. Campylobacter spp., es una bacteria patógena que afecta al hombre, causando diarrea y otras enfermedades como septicemia, meningitis o complicaciones, como artritis reactivas y el Síndrome de Guillian-Barré (GBS), aunque se conocen las enfermedades que pueden provocar poco se sabe de los mecanismos de patogenicidad involucrados. Los factores de virulencia que más se han relacionado con patogenicidad son la motilidad por la presencia de flagelos, la capacidad de adherencia e invasión a la célula eucarionte y la producción de citotoxinas.
\end{abstract}

El conocimiento de la naturaleza, de la regulación y de los mecanismos de acción de los factores de virulencia de Campylobacter spp., es indispensable para la prevención y tratamiento de esta enfermedad.

Palabras clave: Campylobacter spp., Factores de virulencia, Enfermedades transmitidas por alimentos.

\section{Introducción}

Campylobacter spp., es una bacteria zoonótica, agente causal de la campilobacteriosis una enfermedad transmitida por los alimentos (ETA). Este microorganismo tiene una gran importancia socioeconómica tanto en países desarrollados como en vías de desarrollo, provocando incluso más casos de diarrea transmitida por los alimentos que Salmonella (Organización Mundial de la Salud, 2011). En los países desarrollados, es el primer agente de diarrea en el ser humano y el segundo o tercero en las naciones en vías de desarrollo, como es el caso de Chile. El principal reservorio de Campylobacter spp., son las aves de corral (García et al, 2009). En los últimos años, a nivel mundial el consumo de carne de pollo y sus subproductos se ha sindicado como responsable de un alto número de casos de campylobacteriosis en la población humana, siendo los más afectados los niños, ancianos y personas inmunodeprimidas (Silva et al, 2011). Sin embargo, no todos los casos de campilobacteriosis pueden ser explicados por consumo de carne de pollo, y es importante señalar además, que las bacterias del género Campylobacter se encuentran ampliamente distribuidas en la naturaleza, reconociéndose como portadores naturales a una gran variedad de animales, tanto domésticos como de vida silvestre (Fernández et al., 2007).

Varias especies de Campylobacter han sido reconocidas como patógenas para el ser humano y su transmisión se realiza vía oral-fecal, a través del 
consumo de alimentos o agua contaminada, o bien por contacto directo con los animales reservorios. Dentro del grupo Campylobacter hay veinticuatro especies, pero las especies C. jejuni, C. lari y C. coli son las que causan más enfermedad en humanos (Fernández et al., 2007). Como se señaló en un gran número de países desarrollados, se ha observado que la incidencia de infecciones por Campylobacter spp., notificadas ha incrementado enormemente. Reportes realizados por la European Food Safety Authority (EFSA) y el European Centre for Disease Prevention and Control (ECDC), indican que en los últimos años la campylobacteriosis ha sido la zoonosis más notificada. Por otra parte, cabe destacar, que existe un alto número de casos que no son notificados, por lo que la tasa de infección real es aún mayor, con estos antecedentes, se han realizado estimaciones en las que la prevalencia de campilobacteriosis sería entre un 7,6 y 100 veces más alta que los valores oficiales declarados en cada país (CDC., 2013).

Los primeros indicios de la enfermedad causada por la infección con cepas de Campylobacter spp., aparecen dentro de los dos a cinco días, aunque este período puede variar entre uno y diez días. La enfermedad puede ir desde un trastorno gastrointestinal leve, hasta una colitis recidivante o fulminante. Dentro de los signos clínicos comunes se observa: diarrea (frecuentemente hemorrágica), dolor abdominal, fiebre, dolor de cabeza, náuseas y/o vómitos, los que suelen durar de tres a seis días. Si bien, las complicaciones son poco frecuentes, se puede observar los siguientes trastornos graves: síndrome de Guillán Barre, artritis reactiva, síndrome urémico hemolítico y septicemia (Organización Mundial de la Salud, 2011).

Por lo general la infección es autolimitada, y los antibióticos son utilizados sólo en casos prolongados y/o de mayor severidad. Los fármacos de elección comúnmente utilizados en la clínica de pacientes humanos son los macrólidos (como eritromicina o azitromicina), fluoroquinolonas (como ciprofloxacino) y tetraciclinas (como doxiciclina), siendo la gentamicina la única droga alternativa utilizada en pacientes críticos (García et al, 2009; Silva et al, 2011).

\section{Taxonomía}

Las especies del género Campylobacter spp., se ubican en la clase Épsilon de las proteobacterias, en el orden Campilobacterales, que incluye las familias Wolinella, Helicobacteraceae y Campylobacteraceae. Esta última comprende los géneros Campylobacter spp y Arcobacter spp (Butzler, 2004). En 1991, una revisión de la taxonomía y nomenclatura del género Campylobacter fue propuesto de acuerdo con Manual de Bergey (Tax, 2005) con 16 especies. Recientemente, se han sugerido especies adicionales, teniendo actualmente 24 potenciales especies dentro del género las que son: C. fetus, C. coli, C. concisus, C. curvus, $C$. gracilis, C. helveticus, C. hominis, C. hyointestinalis, C. jejuni, C. lanienae, C. lari, C. mucosalis, C. rectus, C. showae, C. sputorum, C. upsaliensis, $C$. insulaenigrae, C. peloridis, C. avium, C. subantarticus, C. canadensis, C. cunicolurum, C. volucris, C. ureoliticus.

Los microorganismos del género Campylobacter spp., son bacilos pequeños de $0,2-0,8 \mu \mathrm{m} \times 0,5-5 \mu \mathrm{m}$, móviles, con uno o varios flagelos polares, curvados en espiral. Son capaces de crecer en una atmósfera de $5 \%$ de oxígeno, $10 \%$ de dióxido de carbono y $85 \%$ de nitrógeno, por lo que son bacterias microaerofílicas . La mayoría de las especies de este género crecen a una temperatura de $37^{\circ} \mathrm{C}$, a excepción de C. jejuni, C. coli y C. lari que pueden crecer a $42^{\circ} \mathrm{C}$. La actividad de la oxidasa está presente en todas las especies excepto para C. gracilis. No fermentan ni oxidan carbohidratos, sino que obtienen su energía a partir de aminoácidos, o intermediarios del ciclo de ácidos tricarboxílicos; siendo la mayoría de las cepas resistentes a la cefalotina (Silva, et al; 2011)..

\section{Epidemiología}

La infección con Campylobacter spp., es la mayor causa de infección intestinal en el mundo y tiene un impacto económico significativo (Hughes et al., 2009). Consecuentemente, existe un esfuerzo continuo para identificar un método efectivo de control de este patógeno. La mayoría de las infecciones en humanos (alrededor del 90\%) son causadas por Campylobacter 
jejuni, otras especies dentro del género, incluyendo Campylobacter coli y Campylobacter lari, también pueden causar enteritis en humanos, pero su prevalencia es menor (Hughes et al., 2009). La mayoría de las enteritis en humanos se cree que son el resultado del consumo de comida contaminada primariamente con heces de animales reservorios. Es conocido que la mayoría de las especies animales productivas, cómo aves, rumiantes y cerdos, son portadores de Campylobacter, haciendo su control dificultoso. En cualquier caso, la epidemiologia del Campylobacter no puede ser explicada únicamente por la transmisión de alimentos expuestos, ya que esta bacteria ha sido aislada de una amplia cantidad de muestras obtenidas del medio ambiente, incluyendo muestras de tierra, agua, arena, leche, verduras, mariscos y heces de un gran número de especies domésticas y silvestres, incluidas aves silvestres (Wesley et al., 2000).

\section{Vigilancia de cepas de Campylobacter spp., productoras de enfermedad en pacientes humanos en Chile}

Varios métodos de diagnóstico han sido aplicados para la detección e identificación de este patógeno, siendo el método de cultivo en agares selectivos el "gold estándar", sin embargo, esta metodología puede presentar un alto consumo de tiempo, recursos, y requiere de personal altamente calificado, lo que puede representar una desventaja. Por estas razones en nuestro país, la notificación y derivación desde hospitales de cepas de Campylobacter spp., hacia los laboratorios de referencia es baja, debido principalmente a que la mayoría de los laboratorios que analizan muestras desde pacientes humanos, no estudian este agente por la falta de implementación de técnicas para su diagnóstico. Esto a pesar que desde el año 1983, Campylobacter spp., es un patógeno de vigilancia de laboratorio, según lo establece el reglamento sobre notificación de enfermedades transmisibles de declaración obligatoria indicado dentro del decreto $\mathrm{N}^{\circ}$ 158. Por esto, no existen estadísticas oficiales de la prevalencia de campilobacteriosis en nuestro país.

\section{Vigilancia de cepas de Campylobacter spp., aisladas desde alimentos en Chile}

En el caso de alimentos, este patógeno no se encuentra incluido en el Reglamento Sanitario de los Alimentos (RSA) y los datos de la presencia de especies de Campylobacter en plantas de procesamiento chilenas son limitados y han sido señalados principalmente por Figueroa et al, 2009.

La frecuente presencia de cepas de Campylobacter spp., en pollos broilers, impulsó a las organizaciones de salud pública y comercio internacional a incorporar su control mediante el Análisis de Peligros y Control de Puntos Críticos (HACCP). Esta estrategia está dirigida a identificar y controlar la presencia de patógenos entéricos en todas las etapas de la cadena de alimentaria; particularmente en el transporte y en el procesamiento en el matadero. Food Safety and Inspección Servicie (FSIS) ha propuesto un nuevo enfoque "inspección basada en el riesgo" enfoque respaldado por información científica para proveer a la industria avícola de mejores opciones para el control de la contaminación a fin de producir un producto más seguro. Sin embargo, a pesar de la implementación de estas normativas no se ha cumplido el objetivo de disminuir la prevalencia de Campylobacter en las canales de aves, por lo que se necesita que exista mayor información sobre este patógeno y su control (Figueroa et al., 2009).

\section{Patogenia y factores de virulencia asociados}

Campylobacter spp., es una bacteria patógena que afecta al hombre, causando diarrea y otras enfermedades como septicemia, meningitis o complicaciones, como artritis reactivas y el Síndrome de Guillian-Barré (GBS) (Hughes et al., 2009).

Los síntomas generalmente se presentan después de un período de incubación de 1 a 7 días y la severidad varía desde diarrea acuosa a sanguinolenta, con fiebre y calambres abdominales. La infección es autolimitante, pero puede presentar secuelas de importancia, como las 
anteriormente mencionadas. El conocimiento de la naturaleza, de la regulación y de los mecanismos de acción de los factores de virulencia de Campylobacter son elementos indispensables para la prevención y el tratamiento de esta enfermedad.

En los últimos años, se han identificado muchos factores de virulencia que podrían estar involucrados en la patogenia que produce Campylobacter en el tracto gastrointestinal sin embargo, la asociación entre factores de virulencia y patogenicidad, aún no está totalmente clara debido fundamentalmente a la heterogeneidad de las cepas existentes (Croinín y Backert, 2012).

Los factores de virulencia, que más se han relacionado con patogenicidad son la motilidad por la presencia de flagelos, la capacidad de adherencia e invasión a la célula eucarionte y la producción de citotoxinas (Willison, 2005; Janssen et al., 2008). Los flagelos son necesarios para la colonización del intestino delgado, para que finalmente el patógeno pueda trasladarse desde allí al colon. Se cree que la capacidad de este patógeno para alcanzar el tracto intestinal, es debida en parte a su resistencia al ácido gástrico y también a su resistencia a las sales biliares. Además, el papel de los flagelos es esencial para la supervivencia bacteriana en los diferentes nichos ecológicos que se encuentran en el tracto gastrointestinal. La invasión por su parte, provoca inflamación celular y cuando es acompañada de la producción de citotoxinas, produce una disminución importante en la capacidad de absorción del intestino, provocando el principal síntoma: la diarrea (Silva et al., 2011).

Otro factor de virulencia importante, es el lipopolisacárido (LPS), este factor de virulencia tiene actividad endotóxica típica, como la presente en los LPS de otras enterobacterias. La estructura del antígeno "O" del LPS contiene ácido siálico, semejante a la que se observa en los gangliósidos humanos. Su presencia en las cepas aisladas de pacientes con síndrome de Guillain-Barré (SGB) sugiere un papel de Campylobacter en la patogenia de esta enfermedad. Es así como la mayoría de los pacientes que desarrollan el SGB después de una enteritis por C. jejuni lo desarrollan debido a la producción de anticuerpos IgG que reaccionan con los glangliosidos GM1, GD1a, and GQ1b (Willison, 2005; Janssen et al 2008).

Un factor de virulencia de gran importancia es la capacidad de producción de citotoxinas de distensión (CDT) (Konkel et al 2001). La CDT, está compuesta por tres subunidades codificadas por los genes cdtA, cdtB y cdtC, que provoca en las células eucariotes la detención en fase G2/M del ciclo celular, evitando que estas entren en mitosis, y en consecuencia conduce a la muerte celular (Yamasaki et al., 2006).

Otros genes relacionados con virulencia han sido los genes flaA, cadF, racR y dnaJ, siendo sindicados como responsables de la expresión de la adherencia y colonización; virB11, ciaB y pldA han sido seleccionado cómo los genes responsables de la expresión de la invasión; y el gen wlaN ha sido seleccionado cómo el gen que presumiblemente está involucrado en la expresión de los "mimics" de gangliosidos en el síndrome de Guillian-Barré (Talukder, 2008).

En general la respuesta de las aves a la infección por $C$. jejuni, no conduce a los mismos síntomas y la respuesta inflamatoria patológica que se observa en los seres humanos. C. jejuni puede colonizar pollos en números extremadamente altos, y el sitio primario de la colonización son las criptas del intestino ciego, donde C. jejuni se encuentra en la capa de mucus cerca de la células epiteliales. Los ciegos de las aves son grandes bolsas cerradas, que se encuentran fuera del colon y se encuentra un poco más allá de la unión ileal. Este entorno es, por lo tanto, probablemente similar a la del colon humano. Se ha observado una ligera inhibición de la invasión en células epiteliales humanas por $C$. jejuni en presencia de mucus intestinal aves, lo que sugiere que la mucosidad podría contribuir a la naturaleza asintomática de la infección en las aves (Young et al., 2007).

Sin embargo, una de las diferencias claves entre la infección que produce Campylobacter jejuni en humanos y en aves es que en estas últimas se comporta como un comensal, la explicación es que el número de bacterias que pueden invadir la célula epitelial humana es muy alto respecto a las bacterias que invaden la 
célula epitelial de las aves. Esto sugiere que la adhesión e invasión son etapas críticas que deben ocurrir para que se desarrolle la enfermedad. Entonces, la identificación de factores de virulencia es un proceso clave para poder desarrollar tratamientos efectivos como también investigación respecto de esta enfermedad (Young et al., 2007).

\subsection{Motilidad Bacteriana y Flagelos}

Campylobacter es una bacteria móvil con 2 flagelos bipolares y esta característica es esencial para la colonización de células humanas. El flagelo está compuesto por una flagelina mayor FlaA y una menor FlaB. Existe una clara asociación entre motilidad e invasión en las cepas de Campylobacter (Cróining y Backert, 2012). Existen estudios que han mostrado que el flagelo posee un rol complejo en la patogenicidad que incluye la secreción de proteínas, esto se cree fundamentalmente ya que las especies de Campylobacter no poseen sistemas de secreción tipo 3 o tipo 4 (SST3 y SST4), que son cruciales en otras especies patógenas entericas (Guerry, P., 2007). Konkel y col, han descrito la secreción de 8 proteínas Cia cuando Campylobacter es incubado junto a células de cultivo. Sólo se ha identificado una de estas proteínas $\mathrm{CiaB}$, la mutación del gen ciaB produce una reducción en la capacidad de invasión de Campylobacter a células epiteliales de un $50 \%$. La secreción de proteínas $\mathrm{CiaB}$ requiere la estructura flagelar, es así como la secreción se produce en cepas con mutaciones en el gen flaA o en el gen flaB pero no en cepas con ambos genes mutados a las cuales les falta todo el flagelo (Guerry, P., 2007). Otra característica de la flagelina de Campylobacter es que es una estructura altamente glicosilada y la glicosilación es muy importante en cepas de C. jejuni ya que no se puede ensamblar el flagelo si esta proteína no está adecuadamente glicosilada. Por otra parte la formación de biofilms es mediada por los glicanos de la flagelina. No hay reportes de la formación de biofilms in vivo pero si los hay en diversas superficies inertes, entonces la formación de biolfilms podría facilitar la sobrevida de bacterias en el agua y en el medioambiente. Interesantemente hay estudios que indican la la formación de biolfilms requiere de la presencia del flagelo. En resumen en Campylobacter el rol del flagelo es muy importante para la colonización intestinal sin embrago este factor de virulencia no es solo requerido como sistema de locomoción y quimiotaxis sino además participaría en otros procesos más complejos.

\subsection{Adhesión e Invasión}

Existe una correlación entre el grado de adhesión e invasión de cepas de Campylobacter a células epiteliales de cultivo in vitro, con el grado de severidad de los síntomas clínicos en pacientes infectados con dichas cepas (Dasti et al., 2010). Un factor importante que ha sido investigado es CadF que es expresado en todas las cepas de Campylobacter jejuni y Campylobacter coli y se sabe que participa en la adhesión celular uniéndose a fibronectina. Es interesante señalar que el gen cadF de las cepas de C. coli es diferente del gen cadF de las cepas de C. jejuni por una secuencia de inserción de 39 bp y se ha demostrado en experimentos realizados en cultivos in vitro que $C$. jejuni se une e invade células epiteliales INT-407 mucho más eficientemente que cepas de la especie C. coli. CadF juega un rol doble, por un lado su papel en la adhesión tipo "tiggers" a la célula hospedera por unión a la fibronectina, que está localizada en la superficie celular y por otro lado esta unión entonces produce procesos de señalización para la adhesión tipo tiggers los cuales conducen a la activación de pequeñas GTPasas Rac1 y Cdc42 y que inducen la propia internalización de la bacteria en la célula hospedera (Dasti et al., 2010).

\subsection{Citotoxinas de distensión}

Muchos patógenos Gram negativos producen citotoxinas de distensión o CDT's, esta toxina causa arresto del ciclo celular y muerte celular en cultivo celulares humanos y está compuesta en el caso de Campylobacter por 3 sub unidades codificadas por los genes cdtA, cdtB y cdtC. Se sabe que CdtB ingresa a la célula hospedera y se una en la superficie celular con las proteínas $\mathrm{CdtA}$ y $\mathrm{CdtC}$ produciendo daño en el ADN celular. La subunidad que tiene el efecto es CdtB debido a su actividad DNAasa rompe el DNA y entonces comienza en la célula el mecanismo de reparación que concluye con el arresto celular y la 
muerte de la célula (Ge et al., 2008). Existe evidencia que la producción de CDT contribuye a aumentar la patogenicidad de las cepas de Campylobacter jejuni, ya que prolonga la persistencia de la enfermedad gastointestinal, aumentando la inflamación de la mucosa gastrointestinal y el daño hepático esto observado en ratones susceptibles. Sin embargo, el conocimiento actual del rol de las toxinas CDT es aún muy limitado. Respecto de la epidemiología, en cepas de Campylobacter la toxina CDT es altamente prevalente, sin embargo el efecto citopatico in vivo varía notablemente desde un efecto muy importante hasta incluso estar ausente en algunos aislados (que poseen los genes pero no expresan la citotoxina). En conclusión existe evidencia experimental in vivo e in vitro que la citotoxina CDT es un factor de virulencia que aumenta la sobrevida y la patogenicidad bacteriana y que produce múltiples efectos citopaticos en el hospedero, sin embrago los efectos son dependientes de las señales medioambientales que regulen la expresión transcripcional y traduccional de los genes cdt en los distintos hospederos, por ejemplo las mismas cepas en pollos broiler no producen enfermedad y en pacientes humanos si la producen.

\section{Concusiones}

Campylobacter spp es un patógeno humano de gran importancia en todo el mundo. El conocimiento de la naturaleza, de la regulación y de los mecanismos de acción de los factores de virulencia de Campylobacter es indispensable para la prevención y tratamiento de esta enfermedad. Un progreso significativo se ha realizado en los últimos años, el que ha contribuido a la comprensión de la función de varios factores de virulencia incluyendo la citotoxina de distención así como los genes involucrados en adhesión e invasión, sin embrago todavía este conocimiento es precario y no podemos establecer como se produce realmente la patogenia en células humanas. Por lo tanto, la identificación de los factores implicados en estos procesos es la clave para el desarrollo de terapias para el tratamiento de las infecciones, así como mejorar nuestra comprensión de la patogénesis.

\section{Referencia}

1. Butzler, J. 2004. Campylobacter from obscurity to celebrity. Clinical Microbiology and infection (CMI). 10(10):868-76.

2. Center for Disease Control and Prevention (CDC). 2013. Incidence and trends of infection with pathogens transmitted commonly through foodfoodborne diseases active surveillance network, 10 US, sites, 1996-2012. MMWR. Morb Mortal Wkly Rep. 19, 62 (15): 283-287.

3. Cróínin, T; Backert S. 2012. Host epithelial cell invasion by Campylobacter jejuni: trigger or zipper mechanism?. Fron. Cell. Infect. Microbiol. 2, 25: 1-13.

4. Dasti, J; Tareen, AM; Lugert, R; Zautner, AE; Gross, U. 2010. Campylobacter jejuni: a brief overview on pathogenicity- associated factors and disease- mediating mechanisms. Int. J Med. Microbiol. 300, (4): 205-211.

5. Fernández, H; Vera, F; Villanueva, MP. 2007. Especies de Arcobracter y Campylobacter en aves y mamíferos del sur de Chile. Arch. Med. Vet. 39, (2): 163-165.

6. Figueroa, G; Troncoso, M; López, L; Rivas, P; Toro, M. 2009. Occurrence and enumeration of Campylobacter spp. During the processing of Chilean broilers. BMC Microbiol. 15, 9:94.

7. García, P; Valenzuela, N; Rodríguez, M; León, E; Fernández, H. 2009. Susceptibilidad antimicrobiana de Campylobacter jejuni aislado de coprocultivos en Santiago de Chile. Rev. Chil. Infect. 26,(6): 511-514.

8. Ge, Z; Schauer, D; Fox, J. 2008. In vivo virulence properties of bacterial cytolethal- distending toxin. Cell. Microbiol. 10, (8): 1599-1607.

9. Guerry, P. 2007. Campylobacter flagella: not just for motility. Trends Microbiol. 15, (10): 45-61.

10. Hughes, L; Bennett, M; Coffey, P; Elliott, P; Jones, T; Jones, R; Lahuerta-Marin, A; Leatherbarrow, A; Mc Niffe, K; Norman, D; Williams, N; Chantrey, J. 2009. Molecular Epidemiology and Characterization of Campylobacter spp. Isolated from Wild Bird 
Populations in Northern England. Appl Envirom Microbiol. 75, (10): 3007-3015.

11. Janssen, KA; Cawthraw, SA; Van Pelt, W; Wagenaar, JA; Owen, RJ. 2008. Host-pathogen interactions in Campylobacter infections: the host perspective. Clin. Microbiol. Rev. 21,(3):505-18.

12. Konkel, M. E; Monteville, M. R; Rivera-Amill, V; Joens, L. A. 2001. The pathogenesis of Campylobacter jejuni-mediated enteritis. Curr. Issues Intest. Microbiol. 2, 55-71.

13. Organización Mundial de la Salud. 2011. Campylobacter. [en línea]. $<$ http://www.who.int/mediacentre/factsheets/fs255 /es/index.html >. [consulta: 8-04-2013]

14. Silva, J.; Leite, D.; Fernnades, M.; Mena, C.; Gibbs, P.; Teixeira, P. 2011. Campylobacter spp. as a foodborne pathogen: a review. Front Microbiol. 2, (200):1-12.

15. Talukder, K; Aslam, M; Islam, Z; Azmi, I; Duttad, D. 2008. Prevalence of virulence genes and cytolethal distending toxin production in Campylobacter jejuni isolates from diarrheal patients in Blangladesh. J. Clin Microbiol. 46, (4): 1485-88.

16. Tax, G. 2005. Bergey's Manual of Systematic Bacteriology, Second Edition. Springer-Verlag, New York, USA.

17. Wesly, IV; Wells, SJ; Harmon, KM; Green, A; Schroeder-Tucker, L; Glover, M; Siddique, I. 2000. Fecal Shedding of Campylobacter and Arcobacter spp in dairy cattle. Appl Environ. Microbiol. 66, (5): 1994-2000.

18. Yamasaki, S; Asakuram, T; Faruque, S.M; Deb, R; Ramamurthy, T.2006. Cytolethal distending toxin (CDT): genetic diversity, structure and role in diarrheal disease. Toxin Rev. 25, 61-88.

19. Young, KT; Davis, LM; Dirita, VJ. 2007. Campylobacter jejuni: molecular biology and pathogenesis. Nat. Rev. Microbiol. 5 (9): 665-679. 